\section{As Noções de Espiritualidade do Campo de Estudos da Psicologia Transpessoal Brasileira}

The Notions of Spirituality in the Brazilian Transpersonal Psychology Study Field

Las Nociones de Espiritualidad del Campo de Estudio de la Psicología

Transpersonal Brasileña https://doi.org/10.28998/rpss.e02106003

Recebido em: 22/04/2021

Aceito em: 07/05/2021

Disponível online: 14/06/2021

Autor Correspondente:

Aurino Lima Ferreira

E-mail: aurinolima@gmail.com

Aurino Lima Ferreira ${ }^{1}$ Orcid Id $\mathrm{n}^{\circ}$ https://orcid.org/0000-0002-7883-9549

Silas Carlos Rocha da Silva ${ }^{2}$ Orcid Id nº https://orcid.org/0000-0002-3923-6198

Sidney Carlos Rocha da Silva ${ }^{3}$ Orcid Id no https://orcid.org/0000-0001-8561-5378

Djailton Pereira da Cunha ${ }^{4}$ Orcid Id no https://orcid.org/0000-0002-7883-9549

Divanise Suruagy Correia ${ }^{5}$ Orcid Id no $\underline{\text { https://orcid.org/0000-0001-7293-4169 }}$

1 Universidade Federal de Pernambuco (UFPE), Recife, PE, Brasil

2 Universidade Federal Rural de Pernambuco (UFRPE), Recife, PE, Brasil

${ }^{3}$ Núcleo Educacional Irmãos Menores de Francisco de Assis (NEIMFA), Recife, PE, Brasil.

4 Universidade de Pernambuco (UPE), Recife, PE, Brasil

5 Universidade Federal de Alagoas (UFAL), Maceió, AL, Brasil

\title{
Resumo
}

A Psicologia Transpessoal surge, no cenário brasileiro, no final dos anos 70, com uma agenda de pesquisa e estudos atrelada à inclusão da espiritualidade como dimensão humana e aspecto fundamental na promoção da saúde. A partir de uma revisão sistemática tomada como problematização, apresentam-se as cinco principais noções de espiritualidade mobilizadas no campo acadêmico brasileiro transpessoal: 1) a espiritualidade como o não religioso; 2) a espiritualidade como experiência transformadora; 3) a espiritualidade como o cultivo de valores humanos fundamentais; 4) a espiritualidade como visão integral e 5) a espiritualidade participativa decolonial. $O$ conjunto destas noções pode contribuir não apenas para a complexificação dos estudos da espiritualidade, como também para a ampliação das perspectivas de saúde e o cultivo do bem viver.

Descritores: Espiritualidade; Psicologia Transpessoal; Saúde.

\section{Abstract}

Transpersonal psychology appeared on the Brazilian scene in the late 1970s with a research and study agenda linked to the inclusion of spirituality as a human dimension and a fundamental aspect in health promotion. From a systematic review taken as a problematization, we present the five main notions of spirituality mobilized in the transpersonal Brazilian academic field: 1) spirituality as non-religious; 2) spirituality as a transforming experience; 3) spirituality as a cultivation of fundamental human values, 4) spirituality as an integral view and 5) decolonial participatory spirituality. The set of these notions can contribute not only to the complexity of spirituality studies, but also to expand the perspectives of health and the cultivation of good living.

Descriptors: Spirituality; Transpersonal Psychology; Health.

\section{Resumen}

La psicología transpersonal apareció en el escenario brasileño a fines de la década de 1970 con una agenda de investigación y estudios vinculados a la inclusión de la espiritualidad como dimensión humana y aspecto fundamental en la promoción de la salud. A partir de una revisión sistemática tomada como problematización, se presentan las cinco principales nociones de espiritualidad movilizadas en el campo académico transpersonal brasileño: 1) la espiritualidad como el no religioso; 2) la espiritualidad como experiencia transformadora; 3) la espiritualidad como el cultivo de valores humanos fundamentales, 4) la espiritualidad como visión integral; y 5) la espiritualidad participativa descolonial. El conjunto de estas nociones puede contribuir no solo a la complejidad de los estudios de la espiritualidad, sino también a la expansión de las perspectivas de salud y el cultivo del buen vivir.

Descriptores: Espiritualidad; Psicología Transpersonal; Salud. 


\section{Introdução}

A Psicologia Transpessoal insere-se no movimento psicológico internacional no final dos anos 60 como um desdobramento da então nascente Psicologia Humanista. Abraham Maslow ${ }^{1}$, um dos principais representantes e fundadores das duas abordagens, destacou esta nova perspectiva como a "quarta força" em psicologia e, juntamente com Anthony Sutich, Stanislav Grof, James Fadiman, Miles Vich e Sonya Margulies, definiu uma agenda de estudos e pesquisas na qual a espiritualidade era considerada uma dimensão fundamental para pensar o humano e a promoção de saúde.

De acordo com Vich², Taylor ${ }^{3}$, Friedman e Hartelius $^{4}$, o termo "transpessoal" foi utilizado pela primeira vez por William James em uma palestra realizada em 1905 na Universidade Harvard, colocandoo, segundo Scotton et al. ${ }^{5}$, como o pai da moderna Psicologia Transpessoal ao lado de Abraham Maslow e Stanislav Grof, seus principais fundadores.

Ryan 6:20 destacou quatro grandes contribuições de James para o campo da transpessoalidade: primeiro, "seu interesse na experiência psíquica e religiosa; em segundo lugar, em sua definição da verdadeira ciência e sua refutação do materialismo; terceiro, em seu conceito de consciência e em quarto lugar, em sua defesa da validade da experiência espiritual".

A paternidade do termo pode ainda ser dividida com Carl Jung, pois, como indicou Daniels ${ }^{8}$, apesar de Jung não ter usado diretamente o termo transpessoal em seus escritos, o "inconsciente coletivo" é "überpersönlich" ou "além do pessoal", o que, de acordo com Strohl ${ }^{9}$, conduziu os tradutores ingleses e norteamericanos de Jung ${ }^{7}$, a partir de 1942, a usarem o termo überpersönlich como sinônimo de "transpessoal" para se referir ao "inconsciente coletivo".

Jung $^{7}$ introduziu a palavra alemã überpersönlich na sua teoria psicológica na primeira publicação do artigo "A estrutura do inconsciente", em 1916, no qual über equivale a sobre, além e persönlich, a pessoal. $\mathrm{Na}$ 21 $1^{\text {a }}$ edição brasileira de Jung7:133, optou-se pela palavra suprapessoal para traduzir este termo.
No Brasil, a Psicologia Transpessoal teve como marco de referência inicial o IV Congresso Internacional de Psicologia Transpessoal, ocorrido em Belo Horizonte, em 1978, com a chancela de Leo Matos e Pierre Weil, seus principais representantes na época. Além de reunir as principais representações nacionais e internacionais desta abordagem, este congresso, segundo Grof et al. ${ }^{10}$, propiciou o surgimento da Associação Internacional de Transpessoal (ITA).

A psicologia brasileira amadureceu como profissão no mesmo ritmo da aprovação da Constituição Federal de 1988, da efetivação do Estatuto da Criança e do Adolescente, dos primeiros anos do SUS, da Lei Paulo Salgado propondo uma lógica antimanicomial, para lembrar os rápidos momentos na saúde e na assistência. E amadureceu mais ainda como profissão na primeira década de 2000 , a partir da reformulação e aprovação do Código de Ética da profissão, em 2005, em consonância com outros avanços, como a Lei Maria da Penha, em 2006, enfeixando uma discussão ampla sobre os direitos humanos na sociedade brasileira. Naquele período, a temática da espiritualidade extrapolou a agenda dos estudos transpessoais e passou a ser reconhecida como um importante vetor de educação e saúde ${ }^{11-18}$, no intuito de "[...] incluir áreas e preocupações tradicionais, às quais acrescenta 0 interesse em facilitar o crescimento e a percepção para além dos níveis de saúde tradicionalmente reconhecidos"19:18.

Grof e Grof 20:22 indicaram que "[...] a filosofia dominante da ciência ocidental tem sido o monismo materialista". Isto significa que as diferentes disciplinas científicas, ao descreverem a realidade como o desenvolvimento da matéria, aceitando como verdadeiro apenas o que pode ser quantificável, terminaram por marginalizar a experiência da espiritualidade como elemento transformador e fundamental da vivência humana.

Os valores espirituais têm sido altamente ignorados e substituídos por visões de mundo que limitam e reduzem o ser humano e a vida a considerações racionalistas e materialistas. Entretanto, ressalta-se que essa forma de pensar e se relacionar com os valores espirituais é exagerada, imatura e 
desnecessária. A ciência genuína e a espiritualidade não precisam competir pelo mesmo território. Como bem ressaltaram Wilber ${ }^{21}$, Grof e Grof ${ }^{20}$, o conflito que se instaurou entre a ciência e a espiritualidade decorre do engano fundamental em torno desses termos.

Com base nos argumentos precedentes, e no intuito de evitar esse tipo de confusão, precisa-se debruçar sobre o conceito de espiritualidade a fim de melhor delimitar o seu sentido desde o ponto de vista Transpessoal. Essa tarefa é imprescindível por diferentes razões. Primeiro, porque o termo tem sido normalmente confundido com 0 aspecto religioso dogmático mais estrito; segundo, porque se trata de um conceito complexo; mas, sobretudo, por ser um campo em que a literatura é não apenas vasta, mas, principalmente, diversa - deixando margens para variados significados, interpretações e análises.

Há muito se observa o quanto a temática da espiritualidade tem aberto um leque de perspectivas que pode trazer sentidos controversos e conflitantes, dando origem a ideias feitas ou (mal)feitas que, muitas vezes, pretendem inviabilizar o seu uso ou a sua aplicação. "Um passeio literário sobre as páginas que tratam sobre o tema da espiritualidade nos leva a paisagens que evidenciam nuances várias que terminam por nos deixar com certa perplexidade diante da sua amplitude face os horizontes da nossa humanidade"22:153.

Por esse motivo, o objetivo deste trabalho consiste em apresentar as principais noções de espiritualidade mobilizadas no campo acadêmico brasileiro Transpessoal a fim de aparar algumas arestas e desfazer determinados equívocos e equivocações acerca da temática aqui apresentada.

\section{A revisão}

sistemática

como

\section{problematização}

Este trabalho teve a revisão sistemática como estratégia específica de investigação. A escolha pela estratégia não foi casual, uma vez que o objetivo em questão apresenta o trato com categorias e conceitos teóricos que cobraram e pediram um contato direto com o que já foi registrado na literatura sobre o tema. A potência desse tipo de pesquisa está, portanto, não em repetir teorias ou pensamentos outros; encontra-se, antes, em como o sujeito investigador dá seu ser mesmo a pensar no momento em que se encontra e se debate com uma bibliografia.

Portanto, do ponto de vista operacional, o processo metodológico materializou-se em três movimentos que se interarticulam: a) no primeiro movimento - o qual se denominou de heurístico -, a heurística traduziu a tradicional etapa de levantamento e revisão bibliográfica, pois esta se caracteriza por ser a arte de localização, busca e mapeamento daqueles documentos que interessaram ao problema de pesquisa; b) o segundo movimento - denominado de fichamento crítico - concentrou-se no processo de degustação, por meio de leitura e fichamento dos documentos selecionados na etapa anterior - daqueles documentos focados estritamente nas categorias centrais deste trabalho: espiritualidade e subjetividade ; c) o terceiro movimento - denominado de síntese problematizadora materializou-se no processo de discussão-análise em torno do que foi sistematizado no processo de leitura e fichamento. Diante disso, seguiram-se os parâmetros analíticos da crítica do processo de leitura. De modo prático, com os fichamentos em mãos, cruzaram-se os achados. Isso permitiu perceber as divergências e as convergências em torno do uso da espiritualidade na Transpessoal, bem como a heterogeneidade e o consenso dos dados encontrados.

\section{As Espiritualidades na Perspectiva Transpessoal: cinco eventos}

A compreensão dos usos do termo espiritualidade foi agrupada em cinco categorias: (1) a espiritualidade como um acontecimento não religioso; (2) a espiritualidade como acontecimento de mudança e transformação; (3) o espiritual acontecendo como valores supremos e altruístas; (4) a espiritualidade como acontecimento integral e (5) a espiritualidade participativa decolonial. Esses cinco acontecimentos levaram a um consenso: apesar de, em alguns momentos, a abordagem Transpessoal incluir e valorar as experiências religiosas como importantes para a vida humana - como se observa na visão integral de Ken 
Wilber 23,24 -, a espiritualidade, em momento algum, é sinônimo de dogmas, ritos, institucionalização ou crença de qualquer tipo. De forma muito direta, o espiritual emerge como uma experiência transpessoal.

\section{A espiritualidade como acontecimento não religioso}

Ao analisar os diferentes usos do conceito em questão, o primeiro que salta aos olhos é o espiritual como um acontecimento distinto do fenômeno religioso. Por isso, é importante fazer a ressalva de que a natureza desta discussão é em torno da espiritualidade e não da religiosidade. Como afirmou Tart ${ }^{25}$, embora esses termos não possam ser integralmente separados, pois tal diferenciação é uma simplificação de um fenômeno complexo, as distinções entre um e outro são essenciais em qualquer investigação. Para os teóricos que defendem esse uso, o religioso, diferentemente do espiritual, diz respeito a um sistema de organizações e crenças sociais que se tornaram institucionalizadas.

Essas organizações e esses sistemas de crenças geralmente passam a existir depois das experiências espirituais pelas quais passou o fundador da religião, e ambos incorporam e desenvolvem (com mais ou menos fidelidade) essas experiências iniciais, transformando-as em estruturas sociais, relações, crenças, necessidades e costumes permanentes ${ }^{25: 26}$.

Assim, "para evitar a falta de compreensão e a confusão que no passado comprometeram discussões semelhantes, é essencial estabelecer uma distinção clara entre espiritualidade e religião"20:25, pois, na religião, o que se encontra são doutrinas e práticas que foram institucionalizadas e, consequentemente, socializadas. Nas palavras de Grof e Grof ${ }^{26}$, o episódio religioso compreende uma atividade grupal institucionalizada e organizada que pode tender para a espiritualidade. Isso vai depender se ela é capaz de proporcionar um campo para as descobertas pessoais ou para o florescimento de certos tipos de qualidades no modo de vida do sujeito.

No entanto, a situação é completamente diferente quando se pensa na espiritualidade. Isso porque as experiências espirituais não devem ser entendidas como um sistema de crenças ou dogmas a ser seguido. O sistema de crenças consiste no modo limitado, rígido e formalístico de tratar esse fenômeno. Essa é a razão principal de se fazer a distinção entre a espiritualidade e a religião, além de prevenir a má comunicação e evitar o seu uso indevido.

\section{A espiritualidade como processos de mudança e transformação do sujeito}

Neste segundo uso, diferentemente da religião, a espiritualidade não aparece como um sistema de dogmas e crenças a ser internalizado e em que nada modifica o modo de vida do sujeito. Neste caso, o fenômeno espiritual desponta como experiências fundamentais capazes de transformar a vida de uma pessoa. Se quiser ficar com as explicações mais estritas desse uso, continuou Tart ${ }^{25}$, é importante entender que, na espiritualidade, se encontram aquelas experiências capazes de modificar a vida de um indivíduo e, por isso, são chamadas, pelo pesquisador, de experiências fundamentais, uma vez que transformam o sujeito não em nível externo - como forma de vestir-se, comer ou beber -, mas no modo como este vive a sua vida por inteiro. Aqui, "[...] é preciso enfatizar que isso se aplica à espiritualidade genuína, com base na experiência pessoal, e não significa um apoio a ideologias e dogmas de religiões organizadas"20:25.

Diferentemente da religião, o espiritual aponta, dentro desse segundo uso, para as experiências pessoais que proporcionam, à vida de um indivíduo e à existência em geral, uma qualidade numinosa ${ }^{26,20}$. A qualidade numinosa reside na capacidade de perceberse e relacionar-se com o mundo e a realidade a partir de outros referenciais que não o comum, o normal, o mesmo. É uma experiência capaz de modificar a visão de sujeito e o sujeito por inteiro.

Dentro dos referenciais da Transpessoal, o numinoso é, portanto, um termo que traduz a qualidade da percepção e da vida que se tornou espiritual. Nesse âmbito, a espiritualidade é aquela experiência com o potencial de tornar a visão de um sujeito numinosa, ou seja, o olhar sobre si mesmo e sobre o mundo passa a ser radicalmente diferente. Não casualmente, "a espiritualidade é algo que caracteriza o relacionamento entre a pessoa e o universo e não requer, 
necessariamente, uma estrutura formal, um ritual coletivo ou a meditação feita por um sacerdote"26:47.

De modo ainda mais simplificado, a espiritualidade é entendida aqui como aquelas experiências capazes de transformar a relação de um sujeito com ele mesmo e com o mundo em que vive. $\mathrm{O}$ esforço, portanto, não está em mudar o mundo, nem os outros. Pelo contrário, o trabalho exige uma mudança na forma como as pessoas se relacionam com tudo isso.

De acordo com Tart²5, o fenômeno espiritual faz com que um indivíduo já não seja o mesmo homem ou mulher de antes, pois transformou sua forma de ser e estar no mundo.

Poderia ser perguntado então:

[...] e o que essas transformações significam para nossa vida? A famosa história do aluno zen e de seu mestre dá conta maravilhosamente bem da resposta. O discípulo perguntou ao mestre: "o que o senhor fazia antes de alcançar a iluminação?" O mestre respondeu: "cortava madeira e carregava água". "O que o senhor passou a fazer depois de alcançar a iluminação?" O mestre respondeu: "Cortei madeira e carreguei água". 26:225

Como se pode perceber, nesse segundo uso, o termo espiritual apresenta uma conotação de transformação, de um processo a ser trilhado na intenção de encaminhar o indivíduo a novas formas de experienciar a si mesmo a modos mais amplos em que as maneiras usuais de se ver são modificadas em suas bases.

\section{A espiritualidade acontecendo como a}

\section{aquisição de valores supremos e altruístas}

Sobre o terceiro uso, averiguou-se que é muito comum encontrar a espiritualidade sendo utilizada dentro da perspectiva Transpessoal como sinônimo da aquisição de atitudes e comportamentos impregnados de valores altruístas. Quando usada neste sentido, observase que adentrar nessa experiência significa adquirir, por uma espontaneidade e naturalidade próprias da mudança de visão do sujeito, características de bondade, compaixão, desapego, generosidade, amor, paciência etc.

Nas palavras do cientista Tart: $\mathrm{O}$ que eu quero dizer quando emprego palavras como "espírito" e "espiritual"? Não sei se elas podem ser definidas com a mesma precisão das coisas materiais (por exemplo, geladeira), mas por "espiritual" refiro-me a uma esfera de valores, experiências, realidades e intuições [... $]^{25: 57}$.

Nesses termos, o espiritual remete não somente às experiências do não religioso e de mudanças na forma de ver e viver a si mesmo e à vida, "[...] como também a todos os estados de consciência e a todas as funções e atividades humanas que têm como denominador comum a posse de valores superiores aos comuns - valores éticos, estéticos, heroicos, humanitários e altruístas"27:51.

De modo bem concreto e prático, a espiritualidade, por ser essa experiência de transformação radical com o modo que se vive e não com o que se exerce, provoca consequências de muitas ordens. Podem aliviar várias formas de desordens emocionais e psicossomáticas, assim como dificuldades com relacionamentos interpessoais. Podem também reduzir tendências agressivas, valorizar a própria imagem, aumentar a tolerância para com os outros e elevar sua qualidade de vida $^{26: 48}$

Além disso, traz efeitos na redução da separatividade com as outras pessoas, com a natureza e o mundo. Mas, o mais importante é que essa aquisição de valores supremos e altruístas "[...] são consequências naturais das experiências transpessoais; a pessoa as aceita e as adota voluntariamente, sem a imposição de injunções externas, preceitos, ordens ou ameaças de punição"26:48.

Aqui, a jornada espiritual é "uma aventura por estranhas terras plenas de surpresas, de alegrias e beleza, de dificuldades e até de perigos. Envolve o despertar de potencialidades até então adormecidas [...]"27:51. Assim, as experiências espirituais são ativadoras de valores e potenciais adormecidos (éticos, estéticos, humanitários) que levam um indivíduo, no trabalho de mudança consigo, a adquirir o que Wilber 28 denominou de atitudes especiais como, por exemplo, bondade, amabilidade, compaixão e sabedoria.

\section{A espiritualidade como acontecimento integral}

A partir de uma definição mais abrangente, Wilber23-24 apresentou uma perspectiva integral de conceber a espiritualidade. $O$ uso que esse autor faz procura ser tão inclusivo que termina abarcando o ponto 
de vista da religião. Fundamentado pelo modelo de desenvolvimento integral, denominado de "o grande ninho do ser", Ken Wilber buscou superar dicotomias e confusões em torno do termo.

O esforço de Wilber ${ }^{23}$, ao elaborar uma obra sobre o uso que se faz da espiritualidade como acontecimento integral, é expor que todo o processo de crescimento humano se dá a partir de duas grandes dimensões: uma dimensão horizontal, denominada de translativa, e uma dimensão vertical, chamada de transformadora. No campo horizontal, encontram-se, disse ele, as religiões em sua função de oferecer significado e interpretação para os homens e as mulheres. Já no terreno vertical encontra-se a espiritualidade autêntica, pois exerce a função de transformação radical nos indivíduos.

A dinâmica do desenvolvimento humano a partir da espiritualidade, portanto, configura-se a partir de dois momentos interligados entre si, que são oferecidos por meio, primeiro, da translação (religião interpretativa) e, segundo, pela transformação (espiritualidade autêntica ou religião como libertação radical). Desse modo, a função translativa da religião exerce um papel fundamental para a sociedade ao possibilitar, aos sujeitos, uma visão interpretativa das coisas do mundo e das situações da vida.

Ela age de modo a criar um significado para o self alienado: oferece mitos, histórias, contos, narrativas, rituais e revivescências que, em conjunto, ajudam o self a entender e suportar as pedras e flechas do destino implacável. Normalmente, essa função da religião não necessariamente altera o nível de consciência da pessoa; não provoca transformação radical. Nem provoca, tampouco, uma libertação definitiva do self alienado. Ao contrário, ela consola o self, fortalece o self, defende o self, promove o self. À medida que o self alienado acredita nos mitos, executa os rituais, balbucia as orações ou aceita os dogmas, então crê fervorosamente que será "salvo" ainda nesta vida, pela glória da salvação de Deus ou da proteção da Deusa, ou na vida após a morte, quando ser-lhe-á [sic] assegurada felicidade eterna ${ }^{29: 1}$.

Entretanto, para além do horizontal e translativo oferecidos, na maioria dos casos, pelas religiões, existe uma dimensão vertical no processo de formação humana. $O$ acesso a essa dimensão, que pode ser oferecido pelas religiões (em raríssimos casos), é denominado de espiritualidade autêntica ou espiritualidade que transforma na medida em que $o$ espiritual é o lugar de transformação radical. Ou, se quiser, todo o processo de transformação autêntica refere-se à experiência espiritual.

Nesse caso,

Não fortalece o self alienado; ao contrário, despedaçao completamente - não consolação, mas devastação, não entrincheiramento mas esvaziamento, não complacência, mas explosão, não conforto mas revolução - em síntese, não fortalecimento convencional da consciência mas transmutação e transformação radicais nas profundezas da própria consciência ${ }^{29: 2}$.

Apesar de saber que Ken Wilber utilizou essas duas dimensões para dizer das diferentes funções da religião, parece ficar claro que a espiritualidade não se apresenta em caráter de dogmas, ritos, crenças ou consolo, mas emerge na medida em que o ego vai além de si mesmo e a lógica de manutenção e preservação do pequeno eu é transcendida. Convém ressalvar que a religião pode e deveria incluir os aspectos espirituais, afinal de contas, essa é a sua segunda função. Todavia, percebe-se que a espiritualidade, para Ken Wilber "[...] não é uma questão de crença, e sim de morte do crente; não uma questão de interpretar o mundo, mas sim de transformá-lo; não uma questão de encontrar alívio, mas sim de encontrar o infinito no outro lado da morte. Não é dada importância ao self, ele é cremado"29:2.

Parece mais claro que a espiritualidade, ou aquilo que deveria ser a segunda função da religião, não pode ser outra coisa senão um processo de transformação radical do sujeito por inteiro, um movimento vertical que aponta para uma transgressão dos limites usuais do ego. Para além dessas diferenciações, o autor quis evidenciar que, a fim de evitar confusões em torno da temática da espiritualidade e respeitar os modos translativos como práticas primeiras e menores, mas não menos importantes para o processo de transformação humana, é preciso encarar a espiritualidade de uma perspectiva integral. E "um enfoque integral à espiritualidade teria que articular o melhor do translativo horizontal com o melhor da função transformadora"22:176.

Segundo Wilber ${ }^{24}$, devido a essa perspectiva integral, há várias formas de se fazer uso do termo 
espiritualidade. O fundamental, nesse caso, não é saber qual é a mais correta. O desafio desse uso é, antes de qualquer empreitada, mencionar a que espiritualidade se está referindo. De acordo com Wilber ${ }^{24,28}$, existem, pelo menos, quatro grandes definições para a palavra espiritual: ela pode ser considerada como o nível mais elevado de qualquer linha de desenvolvimento e, aqui, as pessoas consideram a espiritualidade como o ponto máximo a que se chega seja em linha do cognitivo, emocional, moral etc.; o espiritual pode também referirse a uma linha isolada, sendo considerada uma linha à parte de crescimento humano, ou seja, além do cognitivo, afetivo, moral, haveria também a linha espiritual de desenvolvimento; o espiritual pode ainda ser entendido como um estado ou experiência de "pico" extraordinária - o que significa dizer que espiritual pode referir-se àquelas experiências passageiras que levam um indivíduo a dimensões não duais ou transpessoais da existência, de si mesmo, da vida, como, por exemplo, as práticas xamânicas, uma meditação, uma prática devocional etc.; por fim, a espiritualidade pode significar uma determinada atitude especial como o amor, a compaixão, a generosidade, remetendo, assim, às atitudes baseadas em princípios ou valores altruístas, como se pôde perceber na terceira categoria abordada neste trabalho.

Esse esquema integral de olhar o fenômeno em análise pode ser complicado, mas é o mínimo necessário, afirmou Wilber ${ }^{24}$, para conseguir falar da espiritualidade de modo mais coerente e menos confuso. A espiritualidade integral, portanto, busca contemplar, integrar e acolher essas diferentes perspectivas de vivência espiritual desde que se saiba de onde se está falando e a que se está se referindo.

\section{A espiritualidade participativa decolonial}

Ferrer $^{30-31}$ e Heron ${ }^{32}$ propuseram uma espiritualidade participativa no campo dos estudos transpessoais. Uma espiritualidade que vai do individual/subjetivo para o intersubjetivo e coletivo das relações humanas, com reverberações nas comunidades, nas formas culturais e estruturas sociopolíticas.

Para Ferrer, esta perspectiva:
"[...] introduziu a abordagem participativa como uma 'Virada participativa' nos estudos transpessoais e espirituais - uma mudança paradigmática rompendo com as estratégias epistemológicas predominantes na teoria transpessoal (empirismo interior) e pressupostos ontológicos (perenismo)"30:27.

A espiritualidade participativa é cocriada a partir de uma complexa relação de dimensões intrapessoais, interpessoais e transpessoais. Assim, os fenômenos espirituais são frutos de uma relação dialógica e compreendem não apenas uma dimensão, mas toda a gama de faculdades epistêmicas - racional, imaginal, somática, vital e estética. Em suma, não há cisão entre os aspectos imanentes e transcendentes.

A dimensão intrapessoal é regida pelo princípio da equiprocidade, segundo o qual nenhum atributo humano (por exemplo, a cognição, a corporalidade e o afeto) é, de per si, superior em relação aos demais. A cocriação interpessoal da espiritualidade emerge das relações entre os humanos; estas são caracterizadas pela solidariedade e pelo respeito mútuo, considerando que os seres humanos carregam as suas particularidades mais ou menos desenvolvidas em diferentes aspectos e, assim, não podem ser alçados a um lugar de superioridade em função de um determinado aspecto ao qual o meio social reputa importância ${ }^{33}$, daí se reger pelo princípio da equipotencialidade.

A cocriação transpessoal "[...] refere-se à interação dinâmica entre seres humanos encarnados e o mistério no surgimento de insights espirituais, práticas, estados e mundos" $31: 5$. É estruturada a partir do princípio da equipluralidade, que reconhece a diversidade das experiências de enações espirituais, sendo todas elas equivalentes e emancipatórias.

A Associação Brasileira de Pesquisa e Ensino em Psicologia Transpessoal (Abrapet) tem realizado, nos últimos anos, um processo de decolonização das matrizes do poder, do saber e do $\mathrm{ser}^{34}$, embutidos nos estudos transpessoais, no intuito de ampliar os diálogos com os saberes locais, favorecendo as condições de promoção de bem viver. Assim, ao agregar o termo decolonial ao participativo, tem buscado enfrentar os desafios teórico-práticos no estudo da espiritualidade, 
tais como: a) crítica às perspectivas de um pensamento hegemônico, seja em termos globais, por meio da dominação Norte-Sul35-36; b) revisão da perspectiva de um "centrocentrismo" associado às formas de racismos, machismos, xenofobia e homofobia etc.; c) problematização do enviesamento dos universalismos das ciências e da ética; d) análise crítica da supremacia da racionalidade formal técnico-científica em relação a outras ecologias de saberes; e) a revisão da noção de sujeito da modernidade; e f) reflexão sobre a ideologia das identidades fixas.

\section{Considerações finais}

As cinco noções de espiritualidade mobilizadas nos estudos transpessoais convergem no intento da promoção de modos de vida mais saudáveis que incluam a espiritualidade como dimensão humana e promotora de saúde. Indica-se que, mesmo com todas as divergências no uso do termo, parece existir um fio articulador que conduz a um ponto convergente: a espiritualidade, enquanto um dispositivo ético-espiritual, que convida à reflexão vivida sobre o cuidado com a Terra - a "casa comum" a todos, com a natureza e com os humanos e não humanos - pode apresentar problematizações, respostas e orientações para pensar/sentir a des/construção do modelo civilizatório a partir de outros processos de produção do conhecimento que levem o ser humano ao cultivo do princípio do bem viver.

Assim, a Transpessoal, mais do que uma escola de pensamento psicológico, desponta como um caminho ético-espiritual de cultivo de modos de vida comprometidos com a integração das inúmeras divisões que marcam os seres enquanto humanos imersos em uma cultura colonial. A espiritualidade, enquanto termo central da Transpessoal, foi assumida mais para assinalar as experiências por meio das quais os indivíduos modificavam a forma de se relacionar consigo, com o outro e com o mundo no intuito de expansão de fronteiras e menos para consolidar uma escola psicológica fechada nela mesma ou, ainda, referir-se a algo sobrenatural da vida, dogmático ou restritivo.

\section{Referências}

1. Maslow AH. Toward a Psychology of Being. New York: Van Nostrand Company; 1968.

2. Vich MA. Some historical sources for the term "transpersonal". Int J Transpers Stud [Internet]. 1998 [cited 2020 Aug 10]; 20(2):107-10. Available from: https://atpweb.org/jtparchive/trps-20-88-02-107.pdf

3. Taylor E. William James and transpersonal psychiatry. In: Scotton BW, Chinen AB, Battista JR, editors. Textbook of transpersonal psychiatry and psychology. p. 21-8. Michigan: Basic Books; 1996.

4. Friedman HL, Hartelius G. The Wiley-Blackwell handbook of transpersonal psychology. Roboken: Wiley-Blackwell; 2013.

5. Scotton BW, Chinen AB, Battista JR. Textbook of Transpersonal Psychiatry and Psychology. Michigan: Basic Books; 1996.

6. Ryan MB. The transpersonal William James. Transpers Psychol Rev [Internet]. 2008 June [cited 2020 Aug 10]; 40(1):20-40. Available from: https://www.semanticscholar.org/paper/TheTranspersonal-William-James-

Ryan/81306572c96ec0d55b1124e41b45cdd39912ba0f

7. Jung CG. Ab-reação, análise dos sonhos, transferência. Obras Completas. Petrópolis: Vozes; 2008.

8. Daniels M. Shadow, Self, Spirit: Essays in Transpersonal Psychology. Exeter: Imprint Academic; 2005.

9. Strohl JE. Transpersonalism: Ego Meets Soul. Journal of Counseling and Development [Internet]. 1998 [cited 2020 Aug 10]; 76(4):397-403. Available from: https://eric.ed.gov/?id=EJ581185

10. Grof S, Lukoff D, Friedman H, Hartelius G. The Past and Future of the International Transpersonal Association. Int J Dent. 2008 Jan; 27(1):55-62. Doi: 10.24972/ijts.2008.27.1.55

11. Araujo AC, Santana CLA, Kozasa EH, Lacerda SS, Tanaka LH. Effects of a mindfulness meditation course on healthcare students in Brazil. Acta Paul Enferm. 2020 June; 33:01-9. Doi: 10.37689/acta-ape/2020AO0170

12. Behan $\mathrm{C}$. The benefits of meditation and mindfulness practices during times of crisis such as COVID-19. Ir J Psychol Med. 2020 Dec; 37(4):256-58. Doi: 10.1017/ipm.2020.38

13. Votto GG, Carvalho HCW. Psychological well-being and buddhist meditation: an associative study. Estud Interdiscip Psicol. 2019 Dez; 10(3):60-75. Doi: 10.5433/2236-6407.2019v10n3p60

14. Cossia T, Andrade MFR. Contributions of meditation in school. Interfaces da Educ. 2020 Mar; 11(31):153-76. Doi: $10.26514 /$ inter.v11i31.4111

15. Ribeiro RBP. Cultivo da atenção em espaços educacionais: elaboração, implementação e análise de um projeto de cultivo da atenção em uma perspectiva integral [thesis][Internet]. Recife: Universidade Federal de Pernambuco; 2019 [cited 2020 Aug 10]. Available from: https://repositorio.ufpe.br/handle/123456789/37641

16. Arantes MM. Educação emocional integral: análise de uma proposta formativa continuada de estudantes e professores em uma escola pública de Pernambuco [thesis][Internet]. Recife: Universidade Federal de Pernambuco; 2019 [cited 2020 Aug 10]. Available from: https://repositorio.ufpe.br/handle/123456789/34226

17. Bolanos MJS. La Paradoja de la Conciencia Plena en Ausencia de Afectividad Ampliada: La Empatía Distanciada de la Ética en las Intervenciones Basadas en Midfulness y la Cuestionable Normalización Materialista de lo que Nos Hace Humanos [thesis][Internet]. Curitiba: Universidade Federal do Paraná; 2018. Availble from: https://acervodigital.ufpr.br/bitstream/handle/1884/61946/R\%20$\% 20 T \% 20-$

\%20MARIA\%20JIMENA\%20SARMIENTO\%20BOLANOS.pdf?sequ ence $=1$ \&isAllowed $=y$

18. Silva SCR. A espiritualidade na perspectiva transpessoal: contribuições para repensar o sujeito da educação [dissertation][Internet]. Recife: Universidade Federal de 
Pernambuco; 2015 [cited 2020 Aug 10]. Available from: https://repositorio.ufpe.br/handle/123456789/16769

19. Vaughan F, Walsh RN. Além do ego. Dimensões transpessoais em Psicologia. São Paulo: Cultrix; 1997.

20. Grof S, Grof C. Respiração Holotrópica: uma nova abordagem de autoexploração e terapia. Rio de Janeiro: Capivara; 2011.

21. Wilber K. Um Deus Social. São Paulo: Cultrix; 1983.

22. Ervedosa G, Portela GS, Oliveira VN. Espiritualidade. In: Tavares MFA, Azevedo CRF, Bezerra, MA. Tratado de Psicologia Transpessoal: antigos ou novos saberes em psicologia? Natal: EDUFRN; 2012.

23. Wilber K. O olho do espírito. São Paulo: Cultrix; 2000.

24. Wilber K. A visão integral: uma introdução à revolucionária abordagem integral da vida, de Deus, do universo e de tudo mais. São Paulo: Cultrix; 2008

25. Tart CT. O Fim do Materialismo: como as evidências científicas dos fenômenos paranormais estão unindo ciência e espiritualidade. São Paulo: Cultrix; 2012.

26. Grof S, Grof C. A Tempestuosa Busca do Ser: uma guia para o crescimento pessoal através da crise de transformação. São Paulo: Cultrix; 1994.

27. Grof $S$, Grof C. Emergência espiritual: crise e transformação espiritual. São Paulo: Cultrix; 1992.

28. Wilber K. Psicologia integral: consciência, espírito, psicologia, terapia. São Paulo: Cultrix; 2002.

29. Wilber K. Uma espiritualidade que transforma [Internet]. São Paulo: Ari Raynsford; 2005-2021 [cited 2020 Aug 10]. Avaiable from: http://www.ariray.com.br/textossaladeleitura/uma espiritualidade q ue_transforma.pdf

30. Ferrer JN. Revisioning transpersonal theory: a participatory vision of human spirituality. Albany: State University of New York Press; 2001.

31. Ferrer NJ. Participation and the mystery: transpersonal essays in psychology, education, and religion. Albany: State University of New York Press; 2017.

32. Heron J. Participatory spirituality: A farewell to authoritarian religion. Morrisville: Lulu Press; 2006.

33. Ferrer NJ. Participation, metaphysics, and enlightenment Reflections on Ken Wilber's recent work. Approaching Religion. 2015 Nov; 5(2):42-66. Doi: 10.30664/ar.67573

34. Maldonado-Torres, N. Sobre la colonialidade del ser: contribuciones al desarrollo de um concepto. In: Castro-Gómez, Santiago; Grosfoguel, Ramón (Org.). El giro decolonial. Reflexiones para uma diversidade epistémica más allá del capitalismo global. Bogotá: lesco-Pensar-Siglo del Hombre Editores; 2007.

35. Santos BS. A gramática do tempo: para uma nova cultura política. São Paulo: Cortez; 2010

36. Mgnolo WD. The darker side of western modernity: global futures, decolonial options. Durham: Duke University Press, 2011.

\section{Citação:}

Ferreira AL, Silva SCR, Silva SCR, Cunha DP, Correia DS. As noções de espiritualidade do campo de estudos da psicologia transpessoal brasileira. Health and Society Portal Journal. 2021;6(único):e02106003. Doi:10.28998/rpss.e02106003. 